PHYSICAL REVIEW E 93, 069904(E) (2016)

\title{
Publisher's Note: Generalized hydrodynamics model for strongly coupled plasmas
}

[Phys. Rev. E 92, 013107 (2015)]

\author{
A. Diaw and M. S. Murillo
}

(Received 16 June 2016; published 23 June 2016)

DOI: 10.1103/PhysRevE.93.069904

This paper was published online on 30 July 2015 with an error in Eq. (15). Equation (15) should read as

$$
c\left(\mathbf{r}, \mathbf{r}^{\prime}\right)=-\beta v\left(\left|\mathbf{r}-\mathbf{r}^{\prime}\right|\right)-\beta \frac{\delta^{2} \mathcal{F}^{\mathrm{cor}}[n]}{\delta n(\mathbf{r}) \delta n\left(\mathbf{r}^{\prime}\right)} .
$$

The equation has been corrected as of 17 June 2016. The equation is incorrect in the printed version of the journal. 